\title{
DEBERES SOCIETARIOS Y LAS CONSECUENCIAS DE SU INFRACCIÓN: UNA REVISIÓN CRÍTICA A LA APLICACIÓN DE LA RESPONSABILIDAD EXTRACONTRACTUAL
}

\author{
CORPORATE DUTIES AND THE CONSEQUENCES OF THEIR \\ BREACH: A CRITICAL REVIEW OF THE APPLICATION \\ OF NON-CONTRACTUAL LIABILITY
}

\begin{tabular}{|c|c|}
\hline \multicolumn{2}{|c|}{ COMENTARIO DE JURISPRUDENCIA } \\
\hline CÓMO CITAR ESTE ARTíCULO (CHICAGO) & $\begin{array}{l}\text { Cornejo, Pablo A. y Roberto Carrillo. «Debe- } \\
\text { res societarios y las consecuencias de su in- } \\
\text { fracción: Una revisión crítica a la aplicación } \\
\text { de la responsabilidad extracontractual». Re- } \\
\text { vista de Derecho Aplicado LLM UC } 7 \text { (202I). } \\
\text { https://doi.org/Io.7764/rda.0.7.2174I }\end{array}$ \\
\hline \multirow[t]{2}{*}{ REVISTA DE DERECHO APLICADO LLM UC } & $\begin{array}{l}\text { Número } 7 \\
\text { Julio 202I } \\
\text { ISSN: } 245^{2-} 4344\end{array}$ \\
\hline & $\begin{array}{l}\text { Recepción: } 30 \text { de septiembre, } 2020 \\
\text { Aceptación: II de marzo, } 2021\end{array}$ \\
\hline
\end{tabular}




\section{Resumen}

El presente comentario examina la sentencia dictada por la Corte Suprema el 22 de julio de 2019 (rol 21.881-2017). En esta decisión, la Corte reconoce que los socios de una sociedad de responsabilidad limitada pueden demandar la indemnización de los perjuicios sufridos como consecuencia del actuar fraudulento de los socios administradores, quienes incurrieron en conductas que implicaron una desviación de clientela y la consecuente pérdida de utilidades sociales, invocando las reglas de la responsabilidad extracontractual. Se considera especialmente el problema de consistencia que implica integrar dentro de los deberes generales de cuidado característicos de la responsabilidad extracontractual, ciertas obligaciones que presuponen una relación contractual en un marco colaborativo y que son propias de quienes participan en una sociedad, como ocurre con el deber de lealtad y no concurrencia, así como las consecuencias que tiene esta calificación en sede de resolución de controversias.

Palabras clave: Responsabilidad civil, buena fe, contratos, derecho societario, arbitraje.

\section{Abstract}

This text analysis the opinion rendered by the Supreme Court on July 22, 2019 (Case 21,881-2017). In this opinion, the Court recognizes that the partners of a limited liability company can invoke the rules of non-contractual liability when claiming compensation for damages suffered due to the breach of corporate duties owed to other partners. This, when the formers acted in their capacity as managers of the relevant company, incurring in fraudulent activities that involve deviation of clients and the subsequent loss of corporate profits. Special consideration is given to the consistency issue, involved when including certain obligations that entail a contractual relationship within a collaborative setting - such as the duties of loyalty and non-competition - within the general duties of care, as well as the consequences of his qualification to define his submission to the arbitrator's jurisdiction.

Keywords: Civil liability, good faith, contracts, corporation law, arbitration. 


\section{Pablo A. Cornejo}

Universidad Alberto Hurtado

Santiago, Chile

pcornejo@uahurtado.cl

Universidad Alberto Hurtado

Santiago, Chile

pcornejo@uahurtado.cl
Abogado. Licenciado en Ciencias Jurídicas y Sociales de la Universidad de Chile y máster en Derecho Comparado e Internacional de la Universidad de Lausana, Suiza. Profesor de Derecho Civil y de Derecho Internacional Privado en la Universidad Alberto Hurtado, Chile. Actualmente es asociado senior del área de litigios en FerradaNehme y árbitro de la nómina de la Corte de Apelaciones de Santiago.

Lawyer. Bachelor's in Legal Sciences, Universidad de Chile and Master's Degree in Comparative and International Law, University of Lausanne, Switzerland. Professor of Civil Law and Private International Law at Universidad Alberto Hurtado, Chile. He is currently a senior associate in the litigation area at Ferrada Nehme and part of the Arbitration Body of the Santiago Court of Appeals.

\section{Roberto Carrillo}

FerradaNehme

Santiago, Chile

rcarrillo@ug.uchile.cl

FerradaNehme

Santiago, Chile

rcarrillo@ug.uchile.cl
Abogado. Licenciado en Ciencias Jurídicas y Sociales de la Universidad de Chile y LL. M. con una especialización en Derecho Corporativo de la Universidad de Nueva York, Estados Unidos. Actualmente es asociado senior del área de derecho corporativo en FerradaNehme.

Lawyer. Bachelor's in Legal Sciences, Universidad de Chile and L.L.M. with a minor in Corporate Law at New York University, United States. $\mathrm{He}$ is currently a senior associate in the corporate law area at Ferrada Nehme. 


\section{EL CONFLICTO Y SUS ANTECEDENTES}

En 1963 se constituyó la sociedad Aguilera Hermanos Limitada, con el propósito de desarrollar el negocio de fabricación y comercialización de productos elaborados de metal. Después de diversas modificaciones desde el año 2011, la participación en los derechos sociales de Aguilera Hermanos estaba distribuida, por una parte, entre Jorge Aguilera Ros ( $40 \%$ de los derechos sociales), Armando Aguilera Ros (25\%) y Francisco Aguilera Plaza (5\%), quienes formaban un primer grupo dentro de la sociedad; y, por otra, entre Jorge Aguilera Reyes, Juan Aguilera Reyes y Javier Aguilera Reyes, cada uno con 10\% de los derechos sociales, y quienes integraban un segundo grupo. En lo que concierne a la administración de la sociedad y el uso de la razón social, desde 2011 quedó radicada en Jorge Aguilera Ros y Armando Aguilera Ros, quienes debían actuar en conjunto, con un reemplazante designado para cada uno. Esta última es cuestión relevante, pues en la práctica, a partir de este esquema de poderes el segundo grupo obtuvo un poder de veto dentro de las decisiones de la sociedad, dado que a ellos correspondía reemplazar a Jorge Aguilera Ros en caso de impedimento o ausencia, lo que en definitiva ocurrió.

De esta forma, en el momento en que se producen los hechos que motivan la demanda, existían dos grupos dentro de la sociedad, formado el primero por socios que mantenían una alta participación en término de derechos y que al menos formalmente conservaban la administración, pero que en la práctica tenían una baja incidencia en la toma diaria de decisiones dentro de la sociedad; y un segundo grupo, que mantenía una participación menor en término de derechos, pero que se encontraba más involucrado con el desarrollo de los negocios sociales y que se encargaba de tomar las decisiones operacionales.

En efecto, debido al conocimiento que tenían de la operación del giro social, el segundo grupo de socios constituyó en 2011 una segunda sociedad, Industrial y Comercializadora Aguilera Hermanos Limitada, en que participaban Jorge Aguilera Reyes, Juan Aguilera Reyes y Javier Aguilera Reyes, y que compartía el mismo objeto de la sociedad original. Debido a esta última circunstancia, pronto la nueva sociedad comenzó a competir con la más antigua e, incluso, los socios de Industrial y Comercializadora emplearon la segunda sociedad como un mecanismo destinado a desviar la clientela de Aguilera Hermanos en su propio beneficio. Así, en la práctica, cada vez que se recibían cotizaciones dirigidas a Aguilera Hermanos, los socios de Industrial y Comercializadora aprovechaban la posición que ocupaban en la primera sociedad para desviar la solicitud y canalizarla a través de la nueva, que remitía al potencial cliente la cotización a su propio nombre. Para ello, además, se aprovechaba de la confusión que ocasionaba el que ambas sociedades compartiesen la expresión «Aguilera Hermanos» en su razón social. De esta forma, el potencial cliente se desviaba a la nueva sociedad, que celebraba el contrato de compraventa y emitía las correspondientes facturas. Con todo, la que fabricaba los bienes y asumía los costos era Aguilera Hermanos, pues los socios de Industrial y Comercializadora se valían de la capacidad productiva y de la mano de obra de la primera para desarrollar su negocio. Como 
contrapartida, Aguilera Hermanos solo recibía pagos informales y por montos menores a los de la venta celebrada por Industrial y Comercializadora. De esta manera, en los hechos, Industrial y Comercializadora se valió de las instalaciones, bienes y medios tangibles e intangibles de Aguilera Hermanos para desarrollar su propio negocio, lo que implicó un importante perjuicio para la última sociedad y el primer grupo de socios.

Como se aprecia, el contexto que explica el conflicto está dado por la existencia de un grupo dentro de la sociedad Aguilera Hermanos que, debido a la posición que tenía en el desarrollo de los negocios, podía desviar los requerimientos recibidos en su propio beneficio. En este proceso, además, se empleó la similitud en las razones sociales de ambas sociedades para atraer a esos clientes y se aplicaron fondos sociales de Aguilera Hermanos al desarrollo de los negocios particulares de este grupo de socios, a través de su sociedad Industrial y Comercializadora. Por último, esta situación se vería agravada, pues el segundo grupo de socios se benefició de la necesidad de firma conjunta que exigían los estatutos para obstaculizar la normal administración de Aguilera Hermanos, negándose a firmar cheques o a celebrar otros contratos en beneficio del interés social. Como consecuencia de todo este panorama, la sociedad experimentó un decreciente nivel de ventas, una alta factorización de sus deudas y continuas transferencias de dineros a las cuentas personales de sus socios, lo que llevó a que entrara en cesación de pagos y que se iniciara un proceso de ejecución colectiva de sus bienes. ${ }^{1}$

Dos de los socios que integraban el primer grupo, Armando Aguilera Ros y Francisco Aguilera Plaza, decidieron interponer acciones en contra de los tres socios que constituyeron la sociedad Industrial y Comercializadora, por la responsabilidad que les cabe por las acciones destinadas a perjudicar a Aguilera Hermanos, sacarla del mercado y hacerse de sus activos. Esta situación les habría irrogado un daño consistente en la disminución de las utilidades percibidas por la desvalorización de la empresa y por la afectación de la imagen y la marca de Aguilera Hermanos. Como ninguno de los socios demandantes tenía poderes suficientes para representar a Aguilera Hermanos, invocaron una legitimación personal, que se sustentó en los perjuicios sufridos por cada uno a causa de la desviación de las utilidades normales de la sociedad. Así, el daño demandado se identificó con una prorrata de los fondos que se evitó que ingresaran a las arcas sociales, y que se calculó de acuerdo con su participación dentro de la sociedad de cada uno de los demandantes.

Los demandantes fundaron su acción en las reglas de la responsabilidad extracontractual, pese a que el actuar ilícito y los daños sufridos tienen como antecedente inmediato el contrato de sociedad de Aguilera Hermanos. Con el propósito de salvar ese problema,

1 Que corresponde a los autos rol 20.359-20I4, del Séptimo Juzgado de Letras en lo Civil de Santiago. 
los demandantes sostuvieron que la infracción en que habrían incurrido los demandados no guardaría estricta relación con su calidad de socios en Aguilera Hermanos, sino que involucró también la infracción a los deberes generales de conducta, en que habrían incurrido en la administración de la sociedad Industrial y Comercializadora, excediendo, en consecuencia, el ámbito societario de Aguilera Hermanos. Fue por esta última razón que los demandantes fundaron su decisión de recurrir ante la justicia civil, en lugar de solicitar la constitución del arbitraje dispuesto en los estatutos y ordenado por el artículo 227 numeral cuarto del Código Orgánico de Tribunales.

La demanda interpuesta ante el 22..$^{\circ}$ Juzgado de Letras en lo Civil de Santiago fue acogida ${ }^{2}$ y se condenó a los demandados al pago de los beneficios que los actores dejaron de percibir como consecuencia de las conductas previamente descritas, los cuales fueron fijados en CLP 159.331.846 en el caso de Armando Aguilera Ros y en CLP 31.866.369 en el caso de Francisco Aguilera Plaza. En ambos casos, las cifras fueron calculadas de acuerdo por lo informado por un perito judicial el año 2013 y de lo declarado en juicio por la interventora de Aguilera Hermanos, y consideró tanto las diferencias que se producían en beneficio de Industrial y Comercializadora en las operaciones que fueron desviadas, como también la participación de cada uno de los demandantes en el capital de Aguilera Hermanos a la fecha de interposición de la demanda. Con todo, se consideró un período de cinco años para efectos de calcular los perjuicios. Eso último resulta particularmente llamativo, en circunstancias que la acción se sustentó en las reglas de los delitos y cuasidelitos, que establecen un plazo de prescripción de cuatro años (artículo 2.332 del Código Civil). La decisión fue confirmada en todas sus partes por la Corte de Apelaciones de Santiago. ${ }^{3}$ En contra de esta última decisión, demandantes y demandados interpusieron recursos de casación. De ellos, el presente comentario se extiende solo respecto de la impugnación promovida por los demandados, que pretende la invalidación de la sentencia de segunda instancia por incompetencia del tribunal y por la integración de las normas propias del régimen societario a una pretensión extracontractual.

\section{EL RECURSO DE CASACIÓN Y LA DECISIÓN DE LA CORTE}

En lo que concierne a la casación en el fondo, los demandados impugnaron la sentencia definitiva por considerar que los jueces de la instancia incurrieron en un error al momento de resolver la pretensión sobre la base de las reglas de la responsabilidad extracontractual,

2 Sentencia del Decimosegundo Juzgado de Letras en lo Civil de Santiago, rol 6.4. ${ }_{4} 8-20 I_{4}$, 4 de agosto de 2016 .

3 Sentencia de la Corte de Apelaciones de Santiago, rol ı2.332-20ı6, ı6 de marzo de 20ı7. Además de confirmar en todas sus partes la sentencia del tribunal de primera instancia, rechazó el recurso de nulidad formal interpuesto por la demandada. 
en circunstancias que, por sus propias características, se trata de un conflicto intrasocietario. Este problema en la aplicación de la ley se haría especialmente ostensible si consideramos que, para efectos de construir el estándar de cuidado exigido a los demandados, los tribunales recurren a reglas que forman parte de una relación contractual, como ocurre en particular con lo dispuesto en los numerales segundo y cuarto del artículo 404 del Código de Comercio; mientras que, por otra parte, los jueces se abstuvieron de aplicar la sanción expresamente contemplada en el inciso final del artículo mencionado (llevar al acervo común las ganancias y soportar de manera individual las pérdidas) y recurrieron a los remedios propios del estatuto de responsabilidad extracontractual. De esa forma, al acoger una demanda entre socios sustentada en las reglas de la responsabilidad extracontractual, se estaría incurriendo en un vicio, pues se prescindiría de un contrato vinculante entre las partes y de los remedios que específicamente establece la ley para esa relación. Por último, en la aplicación de estas reglas se habría incurrido en un último error de derecho, pues se estaría confiriendo legitimación activa para demandar a un grupo de socios que carece de poderes para representar a la sociedad, en circunstancias que quien experimenta en forma directa los perjuicios alegados es Aguilera Hermanos, sociedad que sufre la pérdida de ingresos y la desviación de clientela, y no cada uno de los socios personalmente considerados.

La Corte decidió rechazar el recurso de casación interpuesto por los demandados, por considerar que en la especie los jueces de la instancia no incurrieron en la errónea aplicación del derecho denunciada. Lo anterior, principalmente por cuanto la acción interpuesta por los demandantes se sustentó en las reglas de la responsabilidad extracontractual y porque consideró eventos que ocurrieron tanto al interior de Aguilera Hermanos como de Industrial y Comercializadora, de manera que los ilícitos denunciados mal podrían quedar comprendidos exclusivamente dentro de la categoría de conflicto intrasocietario. En particular, resulta ilustrativo el considerando cuarto, en que la Corte expresa que

los hechos invocados no suceden únicamente en el marco de la relación societaria habida entre los litigantes, pues también se materializarían en acciones ejecutadas en otros ámbitos, aunque con la misma intención perjudicial que sustenta la acción resarcitoria, todo lo cual evidencia que la materia discutida puede y debe ser conocida por la justicia ordinaria por ser extraña a aquellas que el estatuto social y la ley han reservado para el conocimiento de un árbitro y es ajena también a un procedimiento de quiebra.

Por otra parte, sobre esa misma base se desestima también el problema de la legitimación activa, pues la Corte considera que los daños demandados - en los términos que se pretende en la acción - fueron experimentados directamente por los socios demandantes, pues estarían dados por la pérdida de aquellos ingresos a los que tenían derecho y que, por lo mismo, no tendrían el carácter de una mera expectativa de ganancia. Para ello, la Corte recurre a la naturaleza de la sociedad en cuestión (sociedad de personas) y a los de- 
rechos que confiere a sus socios, que comprenden como una cuestión esencial el derecho a participar de las utilidades por el desarrollo del giro; además de una cuestión de índole más bien procesal, como es el hecho de que la acción impetrada es el único medio que, desde una perspectiva civil, permite examinar los hechos denunciados.

De este modo, el conflicto de las partes excedería del ámbito societario de Aguilera Hermanos, por lo que quedaría así fuera de las materias de arbitraje forzoso previstas en el Código Orgánico de Tribunales y establecido en sus estatutos.

Por último, en lo que se refiere a la errónea aplicación de las normas sobre la responsabilidad extracontractual, debido a la contradicción que importaría la construcción del deber general de cuidado sobre la base de las normas contractuales y de la buena fe - esta última, como módulo integrador de conducta-, la Corte desestimó el vicio denunciado, por considerar que en la especie los jueces de la instancia no están resolviendo la controversia por medio de la aplicación directa de las normas contractuales -inaplicables en la especie, atendida la propia calificación extracontractual de la responsabilidad-, sino que se limitaron a integrar ciertos deberes generales de corrección dentro del estándar de cuidado exigido en el juicio normativo de culpabilidad. Este razonamiento queda particularmente claro en el considerando $27^{\circ}$ de la sentencia de casación, en que la Corte considera que los jueces de instancia no alteraron la causa de pedir, pues el análisis que se efectúa en relación con el artículo 404 del Código de Comercio se hizo con el propósito de determinar el parámetro de conducta exigible a los socios y únicamente en relación a ellos, en circunstancias que el conflicto no se circunscribe en exclusiva al ámbito interior de la sociedad Aguilera Hermanos, sino que también comprende eventos ocurridos dentro de Industrial y Comercializadora. En ese contexto, el actuar de los demandados - desarrollado tanto al interior como fuera de Aguilera Hermanos- da cuenta de un ánimo doloso, que se valió de su calidad dentro de la sociedad para provocar un daño en el patrimonio personal de los actores, por lo que, en consecuencia, la infracción de los deberes societarios debe ser entendida no de una manera aislada, sino como un factor más dentro de una maquinación, que se aviene con el estatuto extracontractual.

Como bien se puede apreciar, la Corte sustenta su razonamiento en la idea de que los deberes impuestos por la ley a los socios no agotan su ámbito de aplicación en las relaciones intrasocietarias y que, por lo mismo, pueden ser utilizados para dotar de un sentido más preciso a los deberes generales de conducta que sustentan la responsabilidad extracontractual, al menos cuando estas infracciones integren una maquinación mucho más amplia. Por otra parte, podría también considerarse que la interpretación sostenida por la Corte Suprema sistemáticamente busca salvar las importantes diferencias que existen, en materia de responsabilidad civil, entre las sociedades de capital —en las que el régimen ha evolucionado hacia un sistema de responsabilidad legal y en que la propia ley contempla 
acciones oblicuas o subrogatorias en protección de los accionistas minoritarios-, ${ }^{4}$ y las sociedades de personas, por vía de limitar una interpretación solo contractual de los remedios de que disponen los socios, en especial en los casos de infracciones particularmente graves a los deberes sociales y de administración desleal.

Esta última circunstancia podría resultar en particular justificable, sobre todo si consideramos el importante déficit que presenta la normativa aplicable a las sociedades de personas en materia de acceso a la jurisdicción y control de las decisiones de administración. Con todo, más allá de las importantes ventajas que presenta esta decisión, en cuanto permite sentar las bases para una lectura más moderna de nuestro derecho de las sociedades, nos parece que incorpora ciertas dificultades que no pueden dejar de ser examinadas.

\section{3· ¿QUÉ PRoblemas JURídicos PRESENTA ESTa decisión?}

Una somera revisión a la evolución del derecho de las sociedades en Chile permite advertir un marcado contraste entre las reiteradas y relevantes reformas en materia de sociedades de capital, frente a la existencia de una normativa mucho más antigua, todavía aplicable a las sociedades de personas. En principio, la especial preocupación que ha tenido nuestro legislador en resolver las cuestiones que se suscitan en el contexto de las sociedades de capital resulta razonable, sobre todo si consideramos que en ella los problemas de administración desleal resultan críticos, habida consideración de las asimétricas posiciones que ocupan las distintas clases de socios que participan en su interior. Por contraste, cuando se trata de las sociedades de personas - y dentro de ellas, en particular, de las sociedades de responsabilidad limitada-, el legislador no se ha encargado de disponer de un régimen especial destinado a resolver los eventuales problemas de agencia.

De esta forma, resulta habitual que los socios no administradores experimenten importantes dificultades para controlar las decisiones del administrador y, en última instancia, removerlo de dicha posición, ${ }^{5}$ como también para obtener una protección adecuada en sede judicial, dado que en principio las consecuencias que presentan las infracciones en que pueden incurrir los administradores son limitadas.

4 Esta acción social puede ser ejercida en forma subrogada, indirecta o derivativa ante la inacción de la sociedad o de su administración, precisamente cuando quien experimenta el perjuicio es la sociedad como consecuencia de la conducta impropia de sus directores o gerentes. Enrique Alcalde, La responsabilidad de los directores de sociedades anónimas (Santiago: Ediciones UC, 20I3), $244^{-2} 5^{2}$.

5 Sea de mutuo acuerdo de todos socios, a través de una reforma de los estatutos, o por decreto judicial, si concurre alguna causa grave que lo haga indigno de confianza o incapaz de administrar útilmente (artículo 2.072, inciso segundo del Código Civil). Álvaro Puelma, Sociedades (Santiago: Jurídica de Chile, 200I), 378-379; María Fernanda Vásquez, Sociedades (Santiago: Thomson Reuters, 2019), 306-307, 404 . 
Por un lado, por aplicación de la Ley 3.918 sobre sociedades de responsabilidad limitada, y por las reglas establecidas para las sociedades colectivas, los socios deben pactar la forma en que la sociedad se administrará y que, de conformidad con la práctica corporativa chilena, por regla general se confía a uno o más socios, quienes pueden actuar en forma individual o en conjunto, según se establezca. Cualquiera sea el caso, si con posterioridad uno de los socios, descontento con las labores del administrador o los administradores de turno, deseare removerlos de dicho cargo, solo podrá proceder a dicha remoción modificando los estatutos de la sociedad en lo relativo a su administración, para lo cual sería necesario la concurrencia de la totalidad de los socios, incluyendo al o los socios administradores cuya remoción se pretende. Esto es radicalmente distinto de las reglas propias de las sociedades de capital, en que existen mecanismos preestablecidos para el control de las decisiones del directorio. Para ilustrar este punto, baste considerar que en virtud de lo dispuesto en el artículo 58 de la Ley 18.046 sobre Sociedades Anónimas, acciones que representan, a lo menos, el $10 \%$ de las acciones emitidas con derecho a voto, tienen el derecho de requerir al directorio de la sociedad que convoque a una junta extraordinaria de accionistas, instancia en la cual dichos accionistas pueden promover, como materia a ser sometida al conocimiento de la junta, la revocación del directorio a cargo de la administración de la sociedad y la designación de uno nuevo.

En cuanto a las soluciones en sede judicial, los socios perjudicados tienen principalmente dos opciones, las cuales podrían complementarse con la aplicación de las reglas contractuales que se aplican al mandato. ${ }^{6}$ La primera es solicitar la remoción judicial del administrador, por concurrir alguna causa grave que lo haga indigno de confianza o incapaz de administrar útilmente, conforme con lo dispuesto en el artículo 2.072, inciso segundo del Código Civil. La segunda es invocar la infracción de los estatutos para configurar la pérdida de la affectio societatis y, sobre esa base, demandar la terminación de la sociedad, conforme con lo dispuesto en el artículo 2.108, inciso segundo del Código Civil. Sin embargo, es fácil advertir que el uso de cualquiera de estos remedios supone dificultades prácticas de importancia, además de eventuales consecuencias económicas perjudiciales para todos los socios. En efecto, que exista un cuestionamiento en sede judicial a la administración puede llevar a una inacción durante el tiempo que dure el juicio, circunstancia agravada por la inexistencia de medidas cautelares aptas para un conflicto de estas características. Desde un punto de vista práctico, el nombramiento de un interventor (artículo 290, numeral segundo del Código de Procedimiento Civil) será útil para corregir las asimetrías de información que existen entre quienes administran y los demás socios, pero no evitará que se consumen los actos en perjuicio del interés social. Por otra parte, en la

6 Alcalde, La responsabilidad..., 64. Para un caso de conflicto intrasocietario entre socios administradores, resuelto por los tribunales civiles a partir de una acción de reintegro de las sumas percibidas a las arcas sociales, véase la sentencia de la Corte Suprema, rol I6.6r8-20I7, 5 de abril de 2018 . 
demanda de terminación no solo existirán los problemas relacionados con la inexistencia de controles adecuados durante la tramitación del proceso, sino que, además, los socios pueden experimentar una pérdida de valor de la sociedad cuya disolución se demanda. Asimismo, no parece tampoco ser un medio especialmente eficaz en aquellos casos en que el conflicto exista solo entre algunos socios, mientras que a los demás les interesa seguir desarrollando sus negocios por medio de la sociedad en cuestión, sea por el know-how desarrollado o por su prestigio. Como se puede advertir, la protección dispuesta desde la ley resulta insuficiente en esta materia, hasta el punto de que pareciera indicar que el legislador entregó la solución de los problemas de administración a la propia previsión de las partes y de sus abogados, por medio de mecanismos contractuales.

Si bien existen ciertas bases que sugieren que en una sociedad de personas las contingencias relacionadas con los conflictos de interés en la administración son menores que en las sociedades de capital, principalmente por la affectio que existe entre los socios y por la alineación que existe entre los intereses del socio administrador y de la sociedad, ${ }^{7}$ en la práctica esta confianza en los controles contractuales y en la previsión de las partes demuestra muchas veces no alcanzar soluciones satisfactorias. Por lo pronto, esto se explica porque el transcurso del tiempo y el cambio en las circunstancias puede afectar el equilibrio en los intereses de los socios, que alguna vez justificó una determinada forma de distribución de los beneficios o un cierto régimen de administración. En este sentido, elementos habituales dentro de las sociedades de personas con una larga duración, como la percepción de los socios acerca de la importancia que tiene su contribución personal al negocio en común, un cambio generacional en quienes participan en la sociedad, o incluso la mayor o menor aversión al riesgo que tienen los socios con el paso del tiempo, puede llevar a la existencia de conflictos dentro de la sociedad, sin que estos se materialicen de inmediato en su terminación. Por lo mismo, resulta llamativo que conflictos como el que debió resolver la Corte Suprema en la sentencia objeto de este comentario no hayan sido abordados antes por el legislador desde una perspectiva civil, y en el último tiempo solo hayan justificado la reciente reforma en materia de delitos contra el patrimonio. ${ }^{8}$

La falta de esa normativa especial que resuelva los conflictos entre los socios, o en relación con la administración de la sociedad, exige volver a la normativa general aplicable a las sociedades de personas, con miras a identificar aquellos elementos que caracterizan la

7 Ricardo Reveco y Juan Pablo Iglesias, «El conflicto de interés en el contrato de sociedad y su regulación en el Código Civil bajo el estatuto de responsabilidad contractual: Comentario al caso Salinero con Rueda», Revista Chilena de Derecho Privado 33 (2019): I45; Alcalde, La responsabilidad..., $6_{3}-64$.

8 Ley 2I.I2I, modifica el Código Penal y otras normas legales para la prevención, detección y persecución de la corrupción, promulgada el ı2 de noviembre de 2018. 
institución y permiten comprenderla. En este caso, dicha vinculación se debe efectuar, en primer término, con la normativa contenida en la Ley 3.918 sobre Sociedades de Responsabilidad Limitada, y, en segundo término, al Código Civil y al Código de Comercio, según corresponda, todavía vigentes en la materia. De acuerdo con estas reglas, la sociedad de personas se concibe en nuestro derecho esencialmente como un contrato de carácter colaborativo, que permite a dos o más personas coordinar sus esfuerzos en común con miras a repartir entre sí los beneficios que de ellos provengan (artículo 2.053 del Código Civil).

La doctrina no ha dudado en considerar como un elemento caracterizante y de la esencia de este contrato, que cada uno de los socios tenga derecho a participar de la utilidad que origine en desarrollo de su objeto y que deba contribuir a soportar las pérdidas que este arroje. ${ }^{9}$ Con todo, este derecho personal que tiene el socio en contra de la sociedad debe ser objeto de una especial regulación dentro de los estatutos, ${ }^{10}$ pues a falta de estipulación diversa, se entiende que se encuentra condicionado a que la sociedad obtenga una utilidad como consecuencia del desarrollo de sus operaciones sociales, lo que solo podrá saberse al momento en que se disponga de los resultados definitivos (artículo 2.070 del Código Civil). ${ }^{11}$ Esto supone, en cierta forma, que la sociedad agotó el fin para el cual fue constituida. Por esta razón, en la práctica es habitual que en los estatutos se disponga que el derecho de los socios a participar de las utilidades sea definido en forma anual, considerando los resultados del ejercicio - como ocurría en el caso de los estatutos de Aguilera Hermanos-y, más aún, que dicho derecho guarde relación con la participación de los socios en la sociedad.

Como el contrato de sociedad tiene un carácter colaborativo y demanda una especial confianza entre los socios, se considera que en este contrato la observancia de una pauta recta de conducta - expresada por la buena fe-debe regir la actuación especial de cada uno de los socios, quienes tienen un deber de lealtad especial que los obliga a obrar rectamente en beneficio de la sociedad, con miras a desarrollar el fin en común. ${ }^{12}$ Este deber se deriva de la idea de comunidad de intereses que subyace a las sociedades de personas $\mathrm{y}$ al hecho de que se trata de un contrato intuito personae. ${ }^{13}$ En el contexto del derecho

Puelma, Sociedades, 73; Vásquez, Sociedades, 294 y ss.

10 Puelma, Sociedades, 75 .

11 Si bien es viable diferir en el tiempo la oportunidad en que repartirán las utilidades sociales, en caso alguno esto podría implicar desconocer el derecho o postergarlo indefinidamente, pues ello podría implicar la nulidad del pacto social al eliminar el derecho a obtener beneficios. Vásquez, Sociedades, $295^{-296 .}$

12 Nerea Iraculis, Conflicto de interés del socio: Cese del administrador nombrado por accionista competidor (Buenos Aires: Marcial Pons, 20I3), 33.

13 Iraculis, Conflicto..., $3^{8 .}$ 
chileno, la necesidad de integrar los deberes de los socios a través del módulo de la buena fe y el respeto de los deberes de fidelidad se justifica especialmente por su calificación como contrato plurilateral o asociativo. ${ }^{14}$

La existencia de estos deberes especiales de fidelidad y la protección del derecho de cada socio a participar de las utilidades permiten justificar deberes como los impuestos por el artículo 404 del Código de Comercio. En este sentido, bien puede entenderse que la prohibición establecida en el numeral segundo, en orden a que los socios no pueden aplicar los fondos comunes a sus negocios particulares y usar en estos últimos la firma social; y en el numeral cuarto, acerca de que los socios no pueden explotar por cuenta propia el ramo de la industria en que opere la sociedad, son una expresión en particular de la naturaleza asociativa del contrato celebrado y se justifican en la medida que prohíben conductas que prima facie pueden ser consideradas contrarias a las legítimas expectativas que tienen los socios al momento de iniciar el desarrollo de un negocio en conjunto, en orden a compartir sus beneficios. Por el contrario, la imposición de estos mismos deberes, en el contexto de otras relaciones en que la existencia de un fin colaborativo en común es ajena, podría resultar contraria a otros valores protegidos por el ordenamiento, como ocurre en particular con la libertad de empresa y la libre competencia, integrantes de nuestro orden público económico. Por otra parte, como es una relación contractual, resulta perfectamente admisible que los propios socios puedan liberar el cumplimiento de estos deberes, siempre que con ello no se niegue el carácter colaborativo del acuerdo o, incluso, que la consecuencia de su infracción quede primero entregada a la voluntad de las partes, expresada en los estatutos. ${ }^{15}$ En particular, esta situación queda bien reflejada en el hecho de que la prohibición dispuesta por el numeral cuarto del artículo 404 exige que el desarrollo del negocio en paralelo se haya efectuado sin el consentimiento de los restantes consocios.

Con todo, lo que resulta más problemático en este esquema es el carácter limitado de los remedios que en principio se ponen a disposición de los socios en caso de infracción. En efecto, de la revisión del artículo 404, numeral segundo del Código de Comercio, pareciera que, en caso de que uno de los socios aplique fondos comunes al desarrollo de sus negocios particulares, los restantes socios solo pueden obligarlo a llevar a la sociedad las ganancias que hubiere obtenido, o bien pueden decidir excluirlo de la sociedad, sin perjuicio del derecho de la sociedad como persona distinta a demandar la restitución de los fondos o la indemnización de los perjuicios sufridos. Esta regla no nos otorga una pauta clara para otras variantes que se puedan presentar, como ocurriría en el caso de que uno de los socios emplee fondos comunes para los negocios de un tercero, como podría ser otra sociedad

\footnotetext{
14 Puelma, Sociedades, $35^{2}$.

15 Puelma, Sociedades, 355 .
} 
en que participa. Por otro lado, en el caso del artículo 404, numeral cuarto, el socio infractor estará obligado a llevar al acervo común las ganancias y soportar personalmente las pérdidas (artículo 404, inciso final); solución que puede dar lugar a una discusión en torno a quién sufre el perjuicio en el caso en cuestión, pues estaríamos propiamente en presencia de una regla de protección de la sociedad contra la competencia desleal y abuso del derecho, ${ }^{16} \mathrm{y}$ no del interés de cada uno de los socios considerados en forma individual.

Como se puede apreciar, en este esquema no se incorpora la indemnización de los perjuicios que personalmente pueda sufrir uno de los socios como consecuencia de la infracción a los deberes de lealtad por parte de otro, cuestión que puede llevar a considerar que dicho remedio se encuentra excluido. Esta conclusión preliminar se vería confirmada si consideramos que, en todos los casos examinados, el interés de los socios solo es protegido de manera indirecta, imponiendo al socio infractor la obligación de enterar sus ganancias en la sociedad. Así, el interés que se encuentra protegido primordialmente sería el de la sociedad. Sin embargo, esta lectura es problemática en la práctica. Primero, porque su operatividad dependerá de que el socio infractor no cuente con un poder de veto en lo que se refiere a la interposición de acciones en representación de la sociedad. Es lo que ocurría en el caso analizado, y fue uno de los elementos que tuvo en vista la Corte al momento de resolver el conflicto. En segundo lugar, porque es una solución que opera estrictamente en el marco de las reglas societarias, lo que importa en la práctica que el reintegro de los fondos al patrimonio de la sociedad primero beneficiará a los terceros que han contratado con ella y luego, solo de existir un remanente, podrá ser distribuido entre los socios. En el caso examinado, esta situación resultaba en particular relevante, dado que se trataba de una sociedad respecto de la cual se había iniciado un procedimiento de ejecución colectiva. De este modo, pareciera ser una solución insuficiente para aquellos casos en que las irregularidades del socio infractor sean de tal entidad que la sociedad, aun con el reintegro de aquellas sumas que sean posible identificar y recuperar, no pueda recuperarse financieramente, sufriendo los restantes socios de todos modos un perjuicio.

Considerando los límites expuestos, resulta razonable que los socios que vieron defraudados sus intereses hayan buscado la forma de afirmar la existencia de un perjuicio de carácter personal, con miras a ser resarcidos de manera directa por aquellos socios a quienes imputan un actuar desleal. Por el contrario, lo que no resulta fácil de explicar es por qué esa solución se obtuvo por vía de recurrir a las reglas de la responsabilidad extracontractual, en lugar de simplemente integrar remedios generales, que son comunes en materia de contratos, a su relación societaria, como por lo demás se han resuelto otros casos en que existieron controversias entre socios a partir de actuaciones efectuadas por los administradores en su propio beneficio. ${ }^{17}$

16 Ricardo Sandoval, Derecho comercial: Sociedades de personas y de capital, tomo I, volumen 2 (Santiago: Jurídica de Chile, 2014), 6r.

17 Sentencia de la Corte Suprema, rol 32.689-20I8, I9 de junio de 20I9, comentada en Reveco e Iglesias, «El conflicto...», I43-I69. 
En efecto, incluso desde la fundamentación sostenida por la Corte, resulta difícil de explicar cuáles son las razones que justifican la integración de deberes especiales de lealtad a partir de módulos que presuponen una relación especial entre las partes - como ocurre con la buena fe-, para efectos de construir el estándar de diligencia propio de la responsabilidad extracontractual. Si la Corte quería ser coherente con una aproximación desde la perspectiva de los delitos civiles, lo que correspondía era contrastar la conducta desarrollada por los demandados con aquel estándar de diligencia que es propio de las relaciones entre extraños y que en nuestro derecho se expresa en la idea del buen padre de familia, quien responde de culpa leve. Si conforme con ese estándar general el actuar de los demandados podía ser calificado de culpable, lo que correspondía era acoger la acción. La existencia de la sociedad y sus deberes especiales no puede constituir un obstáculo que obligue a los socios a tolerar daños que de otra manera serían indemnizables. En particular, se podría llegar a esta conclusión en caso de calificar el actuar de los demandados como una infracción a aquellos deberes generales de lealtad en el tráfico mercantil, reconocidos en materia de competencia desleal por la Ley 20.169.

Por el contrario, una aproximación desde la responsabilidad extracontractual obliga a prescindir de los deberes especiales que existen entre los socios, pues dada su relación con la buena fe, estos son propios de las relaciones contractuales. Los deberes de conducta que puede tener el buen padre de familia para con su prójimo y a partir de los cuales se estructura el edifico de la responsabilidad extracontractual se agotan en el evitar ocasionar daños de manera injusta (alterum non laedere) y en respetar aquellas «exigencias mínimas que se derivan naturalmente de la condición social del hombre y exigen su observancia en cualquier situación» que forman parte de las buenas costumbres, ${ }^{18}$ pues en términos generales nuestro sistema de responsabilidad extracontractual se sustenta en aquellas razonables expectativas que podríamos tener del comportamiento de otro. ${ }^{19}$ Por el contrario, no pueden comprenden aquellos deberes de lealtad o de consideración que presuponen la existencia de una relación especial, como la que existe entre los contratantes o los socios, pues nadie está obligado a actuar procurando el mejor interés de un extraño, ni sería razonable suponer que todas nuestras interacciones sociales se encuentran sujetas a este estándar. Desde esta perspectiva, la decisión de la Corte resulta difícil de justificar, pues no respeta la coherencia interna del sistema de reglas que le sirven de sustento.

Por la misma razón, en la materia tampoco cabría recurrir a la teoría del cúmulo, por cuanto el propio carácter contractual de la normativa que se considera infringida obliga a reconducir el conflicto a través de las reglas especiales que ha dispuesto el legislador

18 Karl Larenz, Derecho de obligaciones (Madrid: Editorial Revista de Derecho Privado, I958), ${ }_{4} 5$.

19 Enrique Barros, Tratado de responsabilidad extracontractual (Santiago: Jurídica de Chile, 2020), 87 . 
para su resolución, y no resultan aplicables las soluciones desarrolladas por nuestra jurisprudencia que reconocen a la víctima el derecho a optar por el resarcimiento en sede extracontractual. Lo anterior, porque no nos encontramos en presencia de las consecuencias civiles de un ilícito penal, ${ }^{20}$ ni tampoco es posible afirmar que en la materia resulta indistinto recurrir a un régimen u otro. ${ }^{21}$ En último término, las reglas contractuales invocadas para configurar la infracción al deber general de cuidado dan cuenta de una determinada forma de equilibrio de los intereses entre los socios y de relaciones de confianza especiales, que solo pueden ser explicadas en el contexto de la relación contractual y que, por lo mismo, pierden su sentido en el marco de las relaciones anónimas, como las que se encuentran en la base de la responsabilidad extracontractual.

Desde un punto de vista de derecho corporativo, tampoco la solución de la Corte pareciera ser adecuada, dado que no entrega reglas claras que permitan definir cuáles son los criterios que confieren legitimación personal a los socios, cuestión excepcional, si consideramos que todos sus derechos se encuentran mediados por la sociedad en la que participan, y cuya personalidad estarían «levantando» para sostener la existencia de un perjuicio. ${ }^{22}$ En términos prácticos, el razonamiento de la Corte supone desconocer a Aguilera Hermanos como un centro de imputación patrimonial independiente, cuestión que demanda un examen más detenido de la situación. Si bien se trata de una circunstancia que, en materia de sociedades de capital, está en la base de las reformas que buscan la protección de los accionistas minoritarios a través del ejercicio subrogado de la acción social que admite el artículo 133 bis de la Ley 18.046, dicha aproximación resulta ajena al razonamiento seguido por la Corte, pues lo que afirma en su decisión es que los socios podrían sostener la afectación de un interés personal e independiente al de la sociedad. Esto no se condice con el tratamiento más favorable que deben recibir los acreedores - que solo pueden dirigirse en contra de la sociedad-, frente a quienes aportan el capital, pues estos últimos - en caso de seguirse el razonamiento de la sentencia- no solo tendrían el derecho a percibir los beneficios que implique el desarrollo del giro, sino también la facultad de demandar a los administradores si por conductas fraudulentas se impide que esos flujos ingresen al patrimonio social.

En la práctica, la Corte, al permitir que el litigio se desarrolle entre las personas naturales detrás de Aguilera Hermanos e Industrial y Comercializadora, estaría reconociendo una forma de la denominada teoría del levantamiento del velo corporativo, pues se

20 René Abeliuk, Las obligaciones (Santiago: Jurídica de Chile, 200I), 834; Barros, Tratado..., I.r6r.

21 Cfr. sentencia de la Corte Suprema, rol 31.06I-20I4, 2i de marzo de 2016.

22 Para una revisión general de los problemas que genera la aplicación de la doctrina del levantamiento del velo, y las tensiones que produce entre la justicia material y la seguridad jurídica, véase Alberto Lyon, Personas jurídicas (Santiago: Ediciones UC, 2006), 65 y ss. 
prescindiría de una de las consecuencias que implica la afirmación de un patrimonio separado para la sociedad, con el propósito de justificar directamente la existencia de un perjuicio por parte de los socios de Aguilera Hermanos; y, lo que resulta más complejo, para efectos de definir la legitimación pasiva y desvincular el actuar de los administradores de la sociedad a cuyo nombre actúan, lo que permite que sus consecuencias se atribuyan directa y personalmente a quien cometió el acto fraudulento, sea que se trate de un socio, de un administrador con poderes para controlar a la sociedad, o bien de una sociedad relacionada. ${ }^{23}$ Lo anterior, sin definir con claridad las condiciones que harían admisible la aplicación de esta teoría, lo que supone un riesgo cierto de alegaciones que instrumentalmente se funden en las reglas extracontractuales, con el propósito de sustraerse de los límites patrimoniales que implica la responsabilidad contractual y el efecto relativo de los contratos (artículo 1.545 del Código Civil).

Por las mismas razones que consideramos, en el caso, que resulta incompatible la integración de los deberes especiales exigidos a los socios por el artículo 404 del Código de Comercio dentro de los deberes generales de cuidado, es que creemos que la controversia debió ser resuelta por un juez árbitro. La disidencia de la ministra Egnem se refirió a este punto, pues en su concepto los hechos invocados por la parte demandante dan cuenta de una contienda entre socios que queda comprendida dentro de la cláusula compromisoria prevista en los estatutos de la sociedad y es, además, una materia de arbitraje forzoso, de acuerdo con lo dispuesto en el artículo 227 numeral cuarto del Código Orgánico de Tribunales. En efecto, de conformidad con lo dispuesto en esta última disposición, deben ser conocidas por parte de jueces árbitros las controversias que se susciten entre los socios, obligación que en este caso en particular se confirmaba por lo dispuesto en los estatutos de Aguilera Hermanos. Creemos que la aplicación de esta disposición a conflictos como el analizado es relevante, pues, como expone Jequier, el convenio arbitral incorporado en el estatuto de la sociedad define y modela la condición de socio, dado que fija sus derechos y obligaciones en el interior de la sociedad, con relación a los restantes socios, de manera que adquiere un carácter que es consustancial al negocio societario y que, por lo mismo, resulta vinculante respecto de todos los restantes socios, en cuanto confiere competencia a un árbitro para conocer de las controversias y excluye la competencia de los tribunales civiles. ${ }^{24} \mathrm{Al}$ momento de permitir a un grupo de socios demandar ante los tribunales

23 Jorge Ugarte, «Fundamentos y acciones para la aplicación del levantamiento del velo en Chile», Revista Chilena de Derecho 39, n. ${ }^{\circ} 3$ (2012): 700. Véase también Lyon, Personas jurídicas, ı66-167, a propósito del límite del principio democrático y el conflicto de interés en que se encuentra el socio administrador que no ejerce las acciones que corresponden al interés social, y que por tanto actúa de mala fe.

24 Eduardo Jequier, El arbitraje en el derecho chileno de sociedades: Arbitrabilidad del conflicto societario mercantil (Santiago: Thomson Reuters, 20I3), I93. 
civiles, la sentencia deja sin aplicar una parte tan sensible del pacto social como es aquella que define el mecanismo de resolución de controversias, desplazando la voluntad de los socios en orden a someterse al arbitraje.

Este último aspecto es también problemático desde la perspectiva de las normas dispuestas por el Código Orgánico de Tribunales, por cuanto supone desconocer los motivos por los cuales el legislador incluyó al conflicto entre socios entre aquellas materias de arbitraje forzoso, ${ }^{25}$ sin que exista un criterio claramente delimitado que permita establecer cuándo un conflicto de estas características quedará fuera del foro arbitral. Esto puede resultar contradictorio con ciertas características propias de los conflictos societarios - como su complejidad, o la necesaria confidencialidad-y genera el riesgo de crear un incentivo para que las partes efectúen calificaciones de sus pretensiones fuera del ámbito previamente definido para el arbitraje, en afectación de la buena fe contractual, del acceso al mecanismo de resolución de controversias pactado por las partes e, incluso, de la preferencia que en principio deben tener los árbitros para resolver acerca de su propia competencia para conocer de un conflicto. Creemos que esta conclusión no se ve alterada por el hecho de que las conductas en que incurrieron los demandados se hayan desarrollado gracias y al alero de otra sociedad, dado que esta conducta fue en último término evaluada a la luz de los deberes especiales que impone el pacto social, y a que la sociedad Industrial y Comercializadora no fue parte del litigio.

Existe una última cuestión relevante en el caso en cuestión, pues la decisión de la Corte podría justificarse materialmente desde la perspectiva de asegurar el acceso a la justicia a los socios que no cuentan con poderes para obrar en representación de la sociedad. Esta es una cuestión fundamental, pues el acceso a la justicia es una garantía que forma parte del debido proceso (artículo 19, numeral tercero de la Constitución) y que integra el derecho a la tutela judicial efectiva, ${ }^{26}$ en términos tales que define a la función jurisdiccional a partir de la facultad que proporciona a los ciudadanos de someter sus conflictos al conocimiento y resolución de los tribunales. En este sentido, más allá de la constatada ausencia de mecanismos idóneos que permitan a los socios actuar en beneficio del interés social y que demandan un desarrollo de las acciones oblicuas en sede de sociedades de personas, el razonamiento de la Corte abre una importante vía en lo que concierne a la

25 Como son la conveniencia de terminar en forma rápida el conflicto y evitar graves perjuicios, disponiendo a una justicia especialmente apropiada, y la necesidad de liberar a las jurisdicciones ordinarias del examen detallado de cuentas y documentos, además de la multiplicidad de incidentes. Patricio Aylwin, El juicio arbitral (Santiago: Thomson Reuters, 20I4), 8I.

26 Gonzalo García y Pablo Contreras, «El derecho a la tutela judicial y el debido proceso en la jurisprudencia del tribunal constitucional chileno», Ius et Praxis II, n. ${ }^{\circ} 2$ (20I3): $244^{-2} 5^{\circ}$. 
protección de los socios ante los actos de la administración. Con todo, debido a las consideraciones previamente expuestas, pareciera que la forma menos disruptiva de asegurar ese derecho es mediante la integración de remedios contractuales - al menos, en lo que se refiere a los socios administradores que sean demandados-, en lugar de recurrir a las soluciones del ámbito extracontractual.

\section{CONCLUSIONES}

El tratamiento de los conflictos entre los socios en el contexto de las sociedades de personas presenta en la actualidad importantes problemas, que dificultan en la práctica la debida protección de los socios frente a graves infracciones a los deberes de lealtad y corrección que impone la existencia de un contrato que persigue el mejor desarrollo del interés en común. Esta situación se torna especialmente compleja cuando las infracciones en que han incurrido algunos socios o administradores de la sociedad ponen a los restantes socios en una situación en que el acceso a la justicia se ve comprometido, como ocurre en aquellos casos en que la primera afectación se experimenta por la sociedad en su patrimonio y solo de manera indirecta puede llegar a afirmarse la existencia de un perjuicio. Con todo, si bien la existencia de estas situaciones - como ocurre en el caso analizado- obliga a examinar con mayor detenimiento la procedencia de otras acciones comunes destinadas a establecer la responsabilidad de los socios o administradores por su actuar ilícito, dichas soluciones no pueden ser obtenidas solo por vía de desconocer que los especiales deberes de confianza defraudados exigen una evaluación de la conducta desde lo contractual.

De esta forma, parece impropio reconocer una suerte de opción a la víctima para decidir en qué sede demandar, cuando la pretensión normativamente no se sustenta en la calificación autónoma de la ilicitud de la conducta a partir de la infracción a deberes generales de cuidado, sino que demanda la integración de los deberes especiales que son propios del contrato. Una solución de estas características no solo afecta la coherencia del sistema de reglas que sustenta el régimen de responsabilidad invocado - contractual o extracontractual-, sino que, paradojalmente, podría terminar por afectar el acceso a la justicia, desde el momento que niega eficacia al mecanismo de resolución de controversias previsto por las partes. Por otro lado, la solución propuesta pareciere generar importantes tensiones con el reconocimiento y límites de la personalidad jurídica, pilar fundamental del sistema moderno de contratación. Con ello no negamos que en determinados casos pueda sustentarse la existencia de una pretensión indemnizatoria entre socios que deba ser conocida por parte de los tribunales ordinarios de justicia. Lo importante es que ello ocurra cuando efectivamente la acción se sustente de manera autónoma en la infracción de deberes generales de cuidado y no en el incumplimiento de deberes especiales que solo pueden ser justificados en el contexto de la especial relación que existe entre dos contratantes, o bien porque el sustento normativo de la pretensión deducida se encuentre en las reglas generales aplicables a la responsabilidad contractual. $\square$ 


\section{BIBLIOGRAFÍA}

- Abeliuk, René. Las obligaciones. Cuarta edición. Santiago: Jurídica de Chile, 2011.

- Alcalde, Enrique. La responsabilidad de los directores de sociedades anónimas. Santiago: Ediciones UC, 2013.

- Aylwin, Patricio. El juicio arbitral. Sexta edición. Santiago: Thomson Reuters, 2014.

- Barros, Enrique. Tratado de responsabilidad extracontractual. Santiago: Jurídica de Chile, 2006.

- García, Gonzalo y Pablo Contreras. «El derecho a la tutela judicial y el debido proceso en la jurisprudencia del tribunal constitucional chileno». Ius et Praxis 11, n. ${ }^{\circ} 2$ (2013): 229-282. https://doi.org/10.4067/ $\underline{\text { S0718-52002013000200007 }}$

- Iraculis, Nerea. Conflicto de interés del socio: Cese del administrador nombrado por accionista competidor. Buenos Aires: Marcial Pons, 2013.

- Jequier, Eduardo. El arbitraje en el derecho chileno de sociedades: Arbitrabilidad del conflicto societario mercantil. Santiago: Thomson Reuters, 2013.

- Larenz, Karl. Derecho de obligaciones. Madrid: Editorial Revista de Derecho Privado, 1958.

- Lyon, Alberto. Personas jurídicas. Cuarta edición. Santiago: Ediciones UC, 2006.

- Puelma, Álvaro. Sociedades. Tercera edición. Santiago: Jurídica de Chile, 2001.

- Reveco, Ricardo y Juan Pablo Iglesias. «El conflicto de interés en el contrato de sociedad y su regulación en el Código Civil bajo el estatuto de responsabilidad contractual: Comentario al caso Salinero con Rueda». Revista Chilena de Derecho Privado 33 (2019):143-169. https:// doi.org/10.4067/s0718-80722019000100143 
PABLO CORNEJO \& ROBERTO CARRILLO - DEBERES SOCIETARIOS Y LAS CONSECUENCIAS DE SU INFRACCIÓN...

- Sandoval, Ricardo. Derecho comercial: Sociedades de personas y de capital. Tomo 1, volumen 2. Octava edición. Santiago: Jurídica de Chile, 2014.

- Ugarte, Jorge. «Fundamentos y acciones para la aplicación del levantamiento del velo en Chile». Revista Chilena de Derecho 39, n. ${ }^{\circ} 3$ (2012): 699-723. https://doi.org/10.4067/S0718-34372012000300005

- Vásquez, María Fernanda. Sociedades. Tercera edición. Santiago: Thomson Reuters, 2019. 